\title{
INTRACELLULAR CATION EXCHANGES IN METABOLIC ALKALOSIS ${ }^{1}$
}

\author{
By J. R. ELKINTON, ${ }^{2}$ R. D. SQUIRES, ${ }^{3}$ AND A. P. CROSLEY, JR.4 \\ (From the Department of Medicine and Hospital of The University of Pennsylvania, \\ Philadelphia, Pa.)
}

(Submitted for publication October 30, 1950; accepted, February 5, 1951)

It is now well known that disturbances in the electrolyte patterns of the intracellular fluid, as well as in those of the extracellular fluid, may play a significant role in many disease states. Darrow and associates (1) have shown in experimental animals that one pattern of associated abnormalities in the two fluid phases involves intracellular potassium deficit plus sodium excess and extracellular bicarbonate excess plus deficit of chloride. Since then evidence of this relationship has been found in a variety of clinical conditions including congenital alkalosis, vomiting, the postoperative state, and syndromes of hyperadrenocortical function such as Cushing's disease and ACTH administration. This evidence has been obtained by utilization of the balance technic during replacement therapy (2-8), by study of the distribution of radioactive sodium (9), and by tissue analyses of skeletal muscle $(10)$ and of erythrocytes $(9,11)$. These observations have suggested that both low potassium intake and hyperadrenocortical function are implicated in the etiology of this disturbance. In addition to these two etiological factors a third has been postulated, namely, impaired renal conservation of the potassium ion (12).

The purpose of the present study is to examine, in a group of patients with metabolic alkalosis and hypokaliemia, 1) the direction and magnitude of intracellular electrolyte abnormalities as revealed by the balance technic, 2) the relation of these abnormalities to the extracellular hypochloremia and elevation of bicarbonate, and 3 ) the relative etio-

1 This work was done in the Chemical and Renal Sections of the Department of Medicine and in the William Pepper Laboratory; the help of the laboratory staffs and of the clinical staff of the Hospital is gratefully acknowledged. Laboratory facilities were aided by grants from the National Heart Institute, U.S.P.H.S., and by the C. Mahlon Kline Fund of the Department of Medicine.

2 Established Investigator of the American Heart Association.

s Fellow of the Department of Medicine.

4 Woodward Fellow. logical roles of gastrointestinal fluid loss, low potassium intake, intrinsic renal dysfunction, and abnormal adrenocortical activity.

\section{EXPERIMENTAL MATERIAL AND METHODS}

Ten patients were studied by the balance technic, eight of whom were followed during fluid replacement therapy and correction of the alkalosis. The diagnoses of these ten patients and their pertinent clinical conditions are listed in Table I.

Fluids and food of known composition were administered intravenously or orally. All excreta were collected and analysed with the exception of formed stools which usually contain insignificant amounts of electrolytes when no salts have been administered by mouth. Sodium and potassium were determined in serum, urine, and nitric acid digests of stools and foods by means of a Barclay internal standard flame photometer according to the methods of Wallace, Holliday, Cushman and Elkinton (13). Chloride was determined in scrum by the method of Eisenman (14), in urine by the Volhard-Harvey method (15); nitrogen was determined by micro- or macro-Kjeldahl. Total $\mathrm{CO}_{2}$ content of serum and blood was measured by the method of Van Slyke and Stadie (16), and $\mathrm{pH}$ determinations were made with the glass electrode or colorimetrically. Creatinine in urine was determined according to the method of Brod and Sirota (17) and in serum according to the method of Bonsnes and Taussky (18). Inulin determinations in serum and urine were made according to the method of Harrison (19); spaces and clearances being determined according to the formulae, $\frac{\mathrm{In}-\mathrm{Out}}{\mathrm{P}}$ and $\frac{\mathrm{UV}}{\mathrm{P}}$, respectively. The method for the determination of urinary 17-ketosteroids was modified from that of Holtorff and Koch (20)..$^{\circ}$

The derived data were calculated according to previous methods (21). The fundamental assumption involved is the equating of the extracellular fluid with the chloride space; this assumption is discussed below. The change in chloride space is calculated from the change in concentration of chloride in serum (corrected for serum water and the Donnan equilibrium), the balance of chloride, and an assumed initial or final volume for the chloride

The laboratory assistance of Mrs. Helen Lightman and Mrs. Claire Tissari is especially acknowledged.

- The determinations of urinary 17-ketosteroids were done in the Endocrine Laboratory under the direction of Dr. F. Curtis Dohan. 
J. R. elkinton, R. D. SQUires, AND A. P. CROSley, JR.

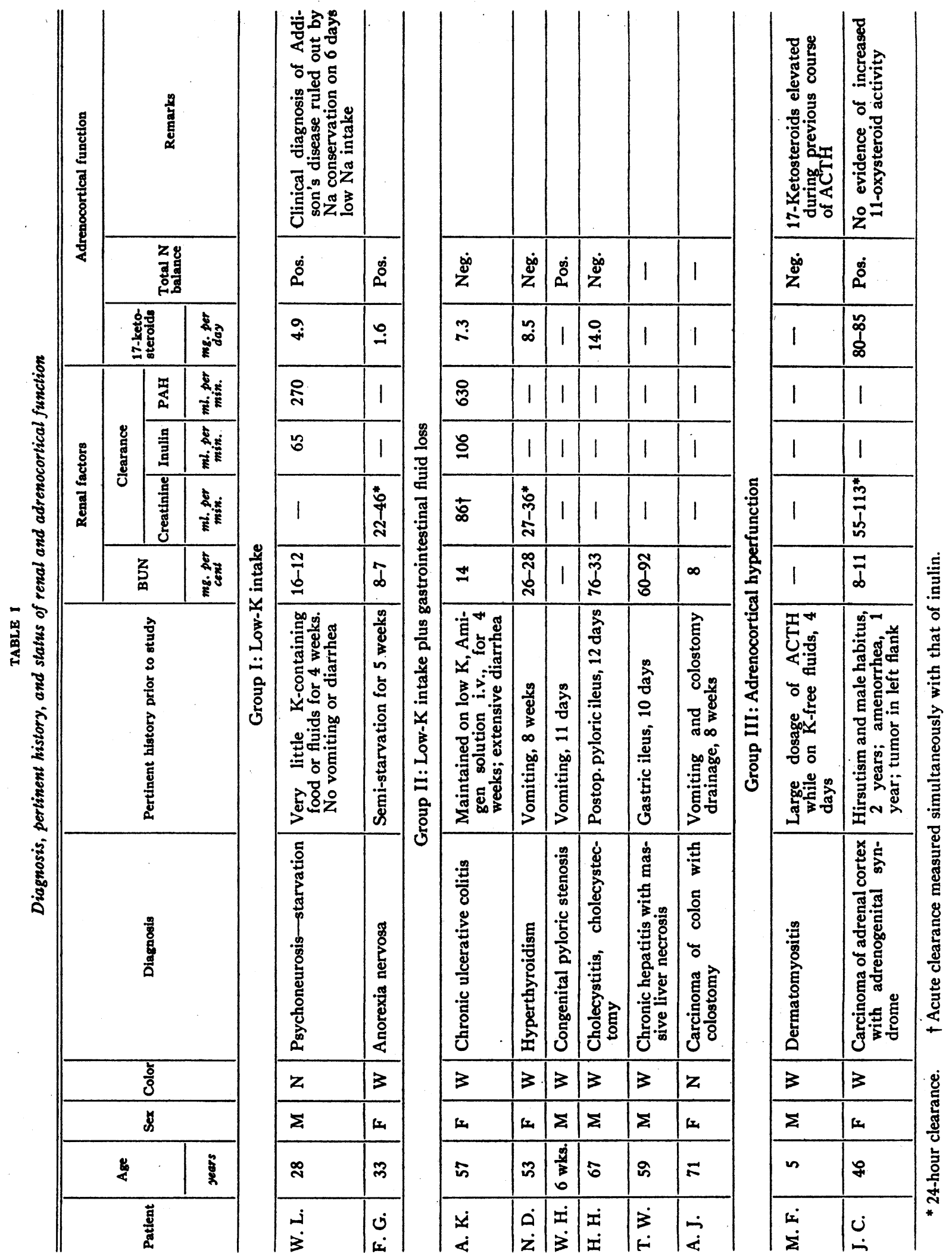




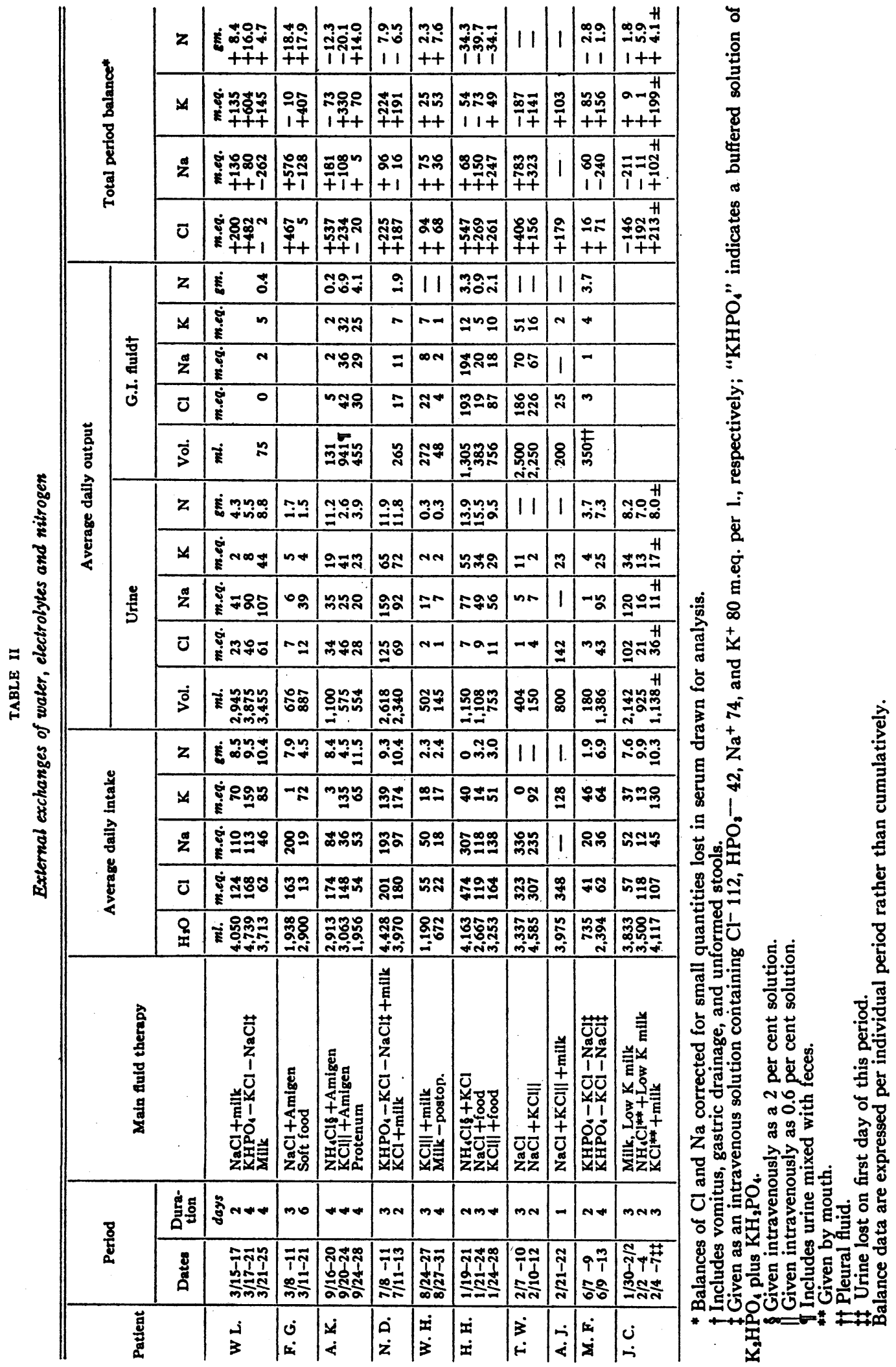




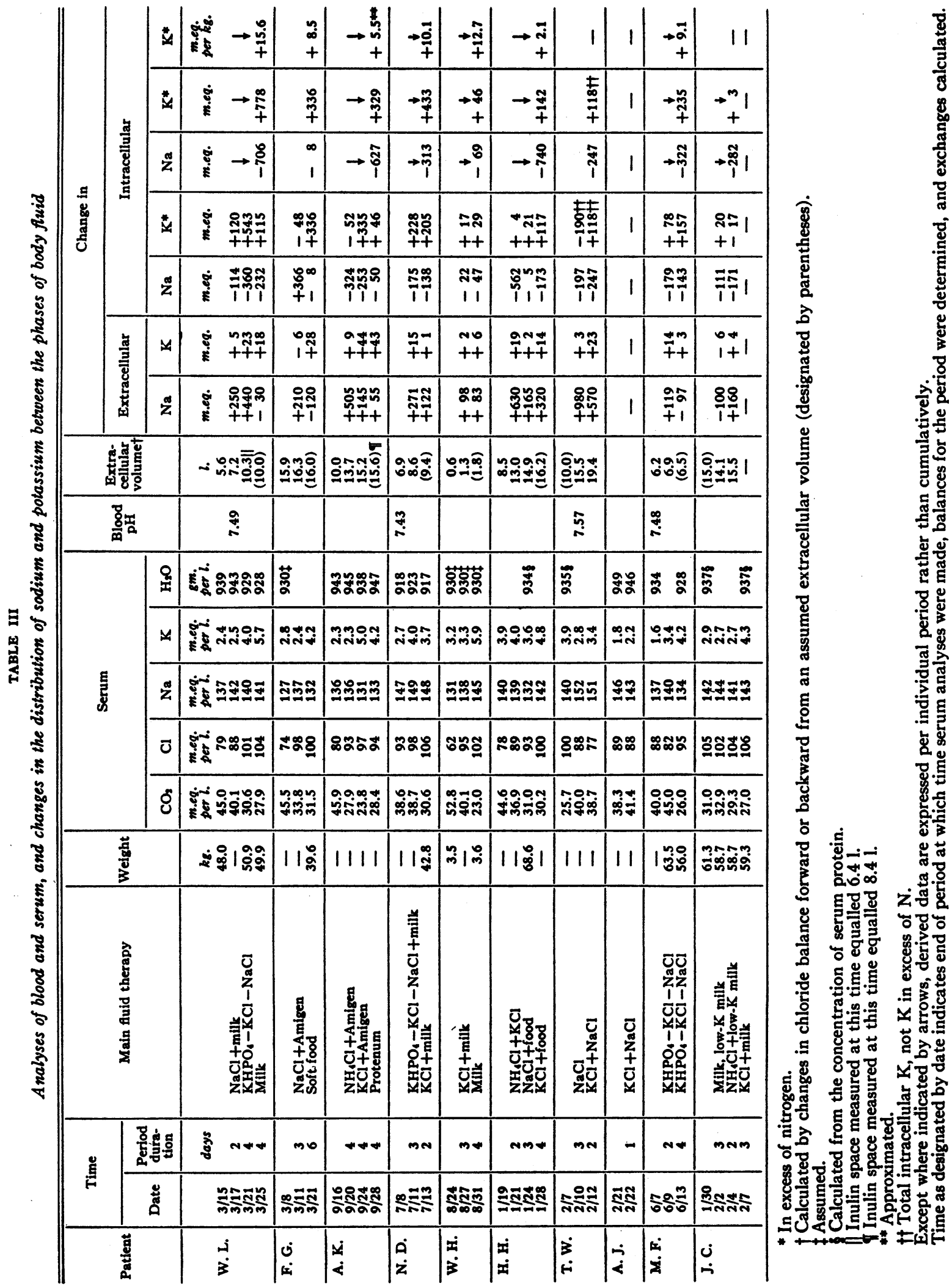


space. The inulin space was determined in two patients at the end of the period of study, but for reasons outlined in the Discussicn were not used in the calculation of change in chloride space. From the values obtained for the volume of extracellular fluid and from the external balances of sodium and potassium, the exchanges of these two ions between the extra- and intracellular phases of the total body fluids are calculated. The results of this latter calculation are little affected by considerable variation in the volume of extracellular fluid as originally assumed or measured.

\section{RESULTS}

The results are presented in Tables I to IV, and in Figure 1. The clinical diagnoses of the patients studied are shown in Table I.

Intracellular cation exchanges. In all but one $(\mathrm{H}$. H.) of the ten patients potassium was retained when administered (Table II). In those patients in whom it was possible to make the calculation, the retained potassium entered the intracellular phase in excess of nitrogen, in amounts up to 15.6 m.eq. per kilogram of body weight (Table III). During treatment, in seven out of ten patients, the balance of chloride was markedly positive in relation to that of sodium (Table II). On the assumption that chloride exchanges were extracellular, it is calculated that large amounts of sodium left the intracellular phase in these patients (Table III). In some of the patients (W. L., N. D., and M. F.) the increment of potassium and the decrement of sodium were of similar magnitude; in others, more sodium was lost from the cells than potassium was gained (Table III). Only two patients were not shown to lose intracellular sodium during treatment, and in one of these, A. J., the sodium exchanges were not measured.

Relation of intracellular cation exchanges to extracellular hypochloremia and bicarbonate elevation. In all the cases except J. C. the elevated bicarbonate concentration in serum was associated with a lowered chloride concentration; and in all the cases during treatment the latter rose as the former fell (Table III). The high levels of bicarbonate were not associated with any marked degree of hypernatremia; during treatment in all cases except M. F. the extracellular sodium concentration remained unchanged or rose. During correction of this hypochloremic alkalosis in eight of ten cases reported the associated intracellular cation exchanges were as follows. In four cases

TABLE IV

Relation of observed chloride exchanges to increments of chloride calculated as necessary to reduce serum $\mathrm{CO}$, concentration to $31 \mathrm{~m} . e q$. per l. (During carly periods before response of alkalosis to therapy)

\begin{tabular}{|c|c|c|c|c|c|c|c|}
\hline \multirow{2}{*}{ Patient } & \multirow{2}{*}{ Period } & \multicolumn{2}{|c|}{ Serum } & \multicolumn{4}{|c|}{ Chloride } \\
\hline & & $\mathrm{CO}_{2}$ & $\mathrm{Cl}$ & Given & Retained & $\begin{array}{l}\text { Excreted in } \\
\text { urine }\end{array}$ & $\begin{array}{l}\text { Increment to } \\
\text { lower } \mathrm{CO}^{*}\end{array}$ \\
\hline W. L. & $\begin{array}{c}\text { deys } \\
0 \\
2\end{array}$ & $\begin{array}{c}\text { m.eq. per } l \text {. } \\
45.0 \\
40.1\end{array}$ & $\begin{array}{c}\text { m.eq. per } l . \\
79 \\
88\end{array}$ & $\begin{array}{l}\text { m.eq. } \\
247\end{array}$ & $\begin{array}{l}\text { m.eq. } \\
200\end{array}$ & $\begin{array}{r}\text { m.eq. } \\
45\end{array}$ & $\begin{array}{r}\text { m.eq. } \\
66\end{array}$ \\
\hline H. H. & $\begin{array}{l}0 \\
2\end{array}$ & $\begin{array}{l}44.6 \\
36.9\end{array}$ & $\begin{array}{l}78 \\
89\end{array}$ & 948 & 547 & 13 & 77 \\
\hline M. F. & $\begin{array}{l}0 \\
2\end{array}$ & $\begin{array}{l}40.0 \\
45.0\end{array}$ & $\begin{array}{l}88 \\
82\end{array}$ & 82 & 16 & 5 & 97 \\
\hline N. D. & $\begin{array}{l}\mathbf{0} \\
\mathbf{3}\end{array}$ & $\begin{array}{l}38.6 \\
38.7\end{array}$ & $\begin{array}{l}93 \\
98\end{array}$ & 603 & 225 & 374 & 67 \\
\hline W. H. & $\begin{array}{l}\mathbf{0} \\
\mathbf{3}\end{array}$ & $\begin{array}{l}52.8 \\
40.1\end{array}$ & $\begin{array}{l}62 \\
95\end{array}$ & 165 & 96 & 72 & 12 \\
\hline A. J. & $\begin{array}{l}0 \\
1\end{array}$ & $\begin{array}{l}38.3 \\
41.4\end{array}$ & $\begin{array}{l}89 \\
88\end{array}$ & 348 & 179 & 142 & 124 \\
\hline J. C. & $\begin{array}{l}\mathbf{0} \\
\mathbf{3}\end{array}$ & $\begin{array}{l}31.0 \\
32.9\end{array}$ & $\begin{array}{l}105 \\
102\end{array}$ & 170 & -146 & 307 & 27 \\
\hline
\end{tabular}

* Calculated from the formula, $E_{2} \times\left(\left[\mathrm{CO}_{2}\right]_{g_{2}}-31\right)$, where $E_{2}=$ extracellular volume at end of the period as derived from an assumed value and the balance of chloride, in liters; $\left[\mathrm{CO}_{2}\right]_{92}=$ concentration of bicarbonate in serum at end of period in m.eq. per 1 . 
(W. L., N. D., W. H., and M. F.) to whom potassium was administered from the start of therapy, intracellular potassium increased and intracellular sodium decreased as the bicarbonate concentration fell. In three others (A. K., H. H., J.C.) to whom $\mathrm{NH}_{4} \mathrm{Cl}$ was administered first, the bicarbonate concentration fell to normal levels and sodium was extruded from the intracellular phase in the absence of any significant uptake of potassium. In two of these three cases (A. K. and J. C.) "excess" cellular potassium was subsequently taken up when the ion was administered; in the third, H. H., potassium was not retained when given. In the eighth case, F. G., the fall in bicarbonate concentration occurred in conjunction with a rise in intracellular sodium followed by a rise in intracellular potassium. The dissociation in some of the cases of the uptake of intracellular potassium from the correction of the elevated bicarbonate concentration and its frequent association with the extrusion of intracellular sodium, as shown in three different cases, is illustrated in Figure 1.

Etiology. The etiological factors responsible for these electrolyte abnormalities are less readily analysed since in nine of the ten cases no observations were made during the development of the alkalosis. A rough etiological classification of the cases has been attempted in Table I. (a) Low$K$ intake: Two cases (Group I) gave a history of a low- $\mathrm{K}$ intake without any concomitant gastrointestinal fluid loss. Both of these cases showed a maximal renal response for conserving potassium at the time the studies were initiated (see below), and neither case showed any evidence of in-
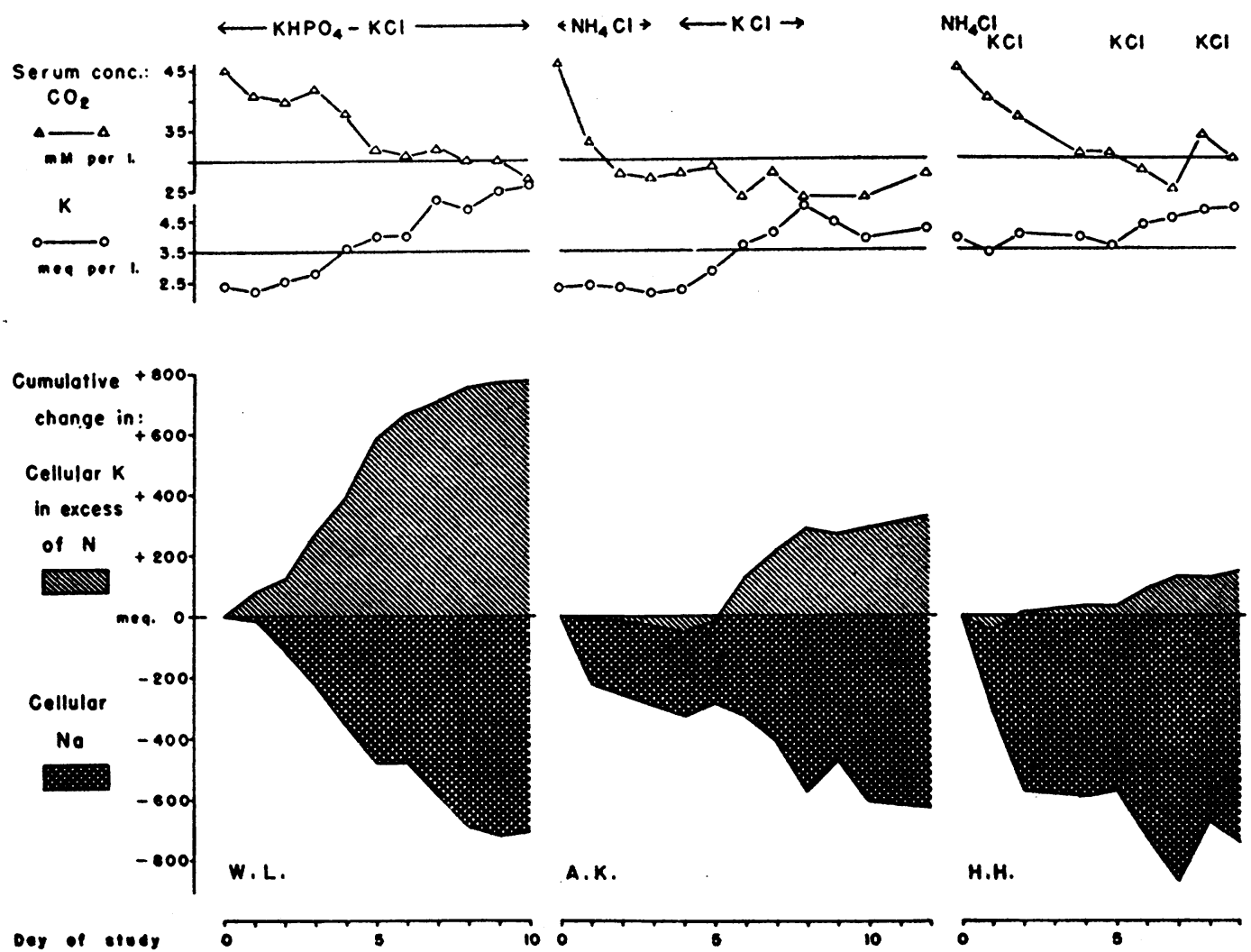

Fig. 1. Relation of Changes in Serum levels of Carbon Dioxide and potassium to Cumulative Changes in Intracellular Cations, during Treatment of Metabolic Alkalosis; Three Types OF RESPONSE

In Patient W. L. intracellular potassium increased and sodium decreased simultaneously with the return of serum $\mathrm{CO}_{2}$ and $\mathrm{K}$ to normal levels. In Patient $\mathrm{A}$. $\mathrm{K}$. during administration of $\mathrm{NH}_{4} \mathrm{Cl}_{\text {the }}$ serum $\mathrm{CO}_{2}$ level returned to normal coincidently with a loss of cellular sodium and prior to an increase in intracellular potassium. In Patient $\mathrm{H}$. $\mathrm{H}$. the serum $\mathrm{CO}_{2}$ level returned to normal in association with a loss of intracellular sodium and without any significant subsequent uptake of cellular potassium. 
creased adrenocortical activity. (b) Gastrointestinal fluid loss: Six cases (Group II) were known to have extensive losses of gastrointestinal fluid containing potassium in addition to giving a history suggestive of a low-K intake. Since, with the exception of A. K., the gastrointestinal fluid lost included gastric fluid, probably greater amounts of chloride were removed than of sodium. Adrenocortical hyperfunction: In Group III are listed two cases in which this factor apparently played a major etiological role. In M. F. the administration of large doses of ACTH, in conjunction with a low intake of potassium, immediately preceded the onset of prostration associated with a severe alkalosis and hypokaliemia. This patient had been shown during a previous course of ACTH to have an adrenocortical response as evidenced by a fall in circulating eosinophils, a rise in 17-ketosteroid excretion, and retention of sodium (22). In the other case, J. C., who had a typical adrenogenital syndrome due to carcinoma of the adrenal cortex, hyperfunction of the gland was the only factor that could be adduced to account for the mild alkalosis and hypokaliemia found. In none of the other cases was there unequivocal evidence of adrenocortical hyperfunction occurring as an etiological factor although thorough and systematic studies of this aspect of the problem were not undertaken. In five of the other eight cases the excretion rate of 17 -ketosteroids was determined and was found to be normal or low (Table I). A negative nitrogen balance which might indicate adrenogenital hyperfunction was found in three of these cases during treatment. Of these A. K. had an extensive loss of nitrogen from the bowel, N. D. was thyrotoxic, and H. H. was in the immediate postoperative period. It is therefore diffcult to use this observation as evidence of primary adrenocortical hyperfunction. (d) Renal dysfunction: kidney function was not systematically studied in this series of cases. Certain observations in some of the cases, however, are worthy of note (Table I). Five cases did not have azotemia; two of these, W. L. and F. G., were patients who apparently developed the alkalosis and potassium deficiency as the result of a low- $K$ intake alone. During the first few days of study at the height of the alkalosis both of these patients excreted such extremely small amounts of potassium that the $\mathrm{U} / \mathrm{P}$ ratio was less than 1.0. Conservation of po- tassium, therefore, was maximal at that time, despite the evidence from clearances of creatinine and inulin that glomerular filtration was impaired.

\section{DISCUSSION}

The observations made in this study confirm the hypothesis that extensive disturbances of intracellular electrolyte exchanges usually occur in states of metabolic alkalosis. Intracellular deficit of potassium, as measured by uptake of the ion during treatment, was certainly present in most of the cases. In Patient W. L. the deficit measured in this way reached a maximum of 15.6 m.eq. per kilogram of body weight, and is of the same magnitude as the largest deficits reported in infant diarrhea (23) or diabetic acidosis (24). If it is assumed that all of this potassium came from skeletal muscle and that this tissue constitutes 40 per cent of the body weight, the deficiency would be equivalent to $39 \mathrm{~m}$. eq. per kilogram of wet muscle and would approximate 40 to 50 per cent of the potassium in the intracellular phase. Such a deficit is quite comparable to those produced experimentally in rats by Darrow (1) and exceeds those found in muscle biopsies taken from clinical cases by Mudge and Vislocky (10).

The demonstration of an excess of sodium in the intracellular phase is less certain. As calculated on the basis of the assumption that the chloride exchanges were entirely extracellular, the intracellular sodium exchange during treatment was negative in all but one of the nine cases in which it was measured. In four of the cases the size of the decrement of cellular sodium was sufficiently close to that of the increment of potassium to suggest that the former cation was being substituted for by the latter. In the other four cases the loss of cellular sodium so far exceeded the uptake of potassium as to obviate any such relationship. The validity of the assumption, however, on which these exchanges of intracellular sodium are calculated, must be questioned. Certainly in most of the cases during treatment the external balance of chloride was much greater in the positive direction than that of sodium. These balances are observed, not derived, data, and would not be invalidated by any unmeasured loss of salt in sweat in which chloride and sodium are present in approximately equal concentrations. The differential secretion of $\mathrm{Cl}$ into gastric fluid which was not lost from the body 
and therefore not included in the measured balance, conceivably might be another source of error. The magnitude of the discrepancies between $\mathrm{Cl}$ and $\mathrm{Na}$ renders this explanation improbable; it is unlikely that, during the course of study in some of the patients, 5 or 61 . of unreabsorbed gastric juice accumulated undetected. The difference between the external balances of these two ions would appear to require some other explanation. An alternative to the interpretation that these disparate balances represented loss of sodium from the cells is that chloride entered the intracellular phase. Physiological evidence for such a phenomenon is not lacking. Conway's (25) theory calls for a small amount of intracellular chloride to balance the extracellular potassium, and Dean (26), Wilde (27), and Burch and co-workers (28) have presented evidence that under certain circumstances chloride may enter the cells of tissues other than gastric mucosa, testes, and ovaries where chloride is a normal intracellular constituent. Evidence in support of the entry of chloride into cells was found in three of the cases reported here, W. H., W. L., and $A . K$. In the infant, Patient W. H., during therapy the chloride space expanded to a volume equivalent to approximately 50 per cent of the body weight which is unexpectedly large for a non-edematous subject even in childhood. A similar finding has been described during treatment of vomiting infants by Danowski and his associates (4), who were unable to attribute it to error in measurement of the chloride balance. In Patients W. L. and A. K. an inulin volume of distribution was determined at the end of replacement therapy. When this volume of distribution was taken as the final volume of extracellular fluid and, from it, and from the chloride balance, the initial volume of extracellular fluid was calculated, the latter was found to be less than 11 . Since such a value is absurd, the conclusion is that either the measurement of the volume of distribution of inulin was in error, or that chloride entered cells. A definitive answer to this problem requires the accurate measurement of the extracellular fluid volume by some independent means, such as inulin, both before and after treatment, so that the intracellular transfer of chloride, if any, can be measured directly. Unfortunately, an opportunity to do this in the present study was not available. The possibility remains, therefore, that chloride entered the intracellular phase during treatment in these cases. But again because of the magnitude of the transfers involved, it seems most unlikely that this did occur to such an extent as to preclude the extrusion of sodium.

Certain conclusions can be drawn in regard to the relationship of these intracellular electrolyte abnormalities to the extracellular hypochloremia and alkalosis. The production of intracellular potassium deficiency and of probable sodium excess by prolonged absence of potassium intake, appeared to result in hypochloremia and elevation of the extracellular bicarbonate concentration. This suygests that under conditions of biological equilibrium or the steady state of adequate renal adjustment, as predicted by Darrow (1), these intracellular disturbances are associated with a diminished tubular reabsorption of chloride despite the presence of hypochloremia. Such a concept receives further support from an analysis of the renal response to chloride administration in some of these cases, as presented in Table IV. In three of the cases tabulated, the extracellular fluid volume was expanding to such an extent that the administered chloride was insufficient to raise the extracellular concentration even if the kidneys had been able to conserve it, i.e., the kidneys excreted less chloride then the increment calculated as necessary to displace the bicarbonate to normal levels. In other words, in these cases, the kidneys had no chance to show conditioning by another factor and the data cannot be used to imply that the circumstances required a maintenance of hypochloremia and alkalosis in the presence of chloride administration. In the other four cases of alkalosis, three of whom had hypochloremia (N. D., W. H., A. J., and $\mathrm{J} . \mathrm{C}_{\text {.) }}$, during the initial days of study chloride was excreted by the kidney in amounts sufficient to have displaced the high bicarbonate had the chloride been conserved. Thus the failure to adjust the abnormal concentrations in the latter cases was not due to unavailability of chloride when neutral salts, $\mathrm{NaCl}$ and $\mathrm{KCl}$, were given. Pitts, Ayer and Schiess (29) have found that, during the acute administration of sodium bicarbonate, as the tubular reabsorption of $\mathrm{HCO}_{3}$ rises to a maximal rate, the reabsorption of chloride is correspondingly depressed; and as a result the total cation concentration in the extracellular fluid is undisturbed. The cases reported here are hardly comparable to these 
experimental subjects of Pitts since ours represent prolonged states of equilibrium maintained in the presence of conditions other than acute loading of excess sodium bicarbonate. Furthermore, if the results of the acute i.v. administration of a single dose of sodium bicarbonate to a normal subject are observed over a period of many hours the initial rise in the rate of renal excretion of chloride is followed by a fall (30); as the elimination of the excess bicarbonate continues the kidneys again conserve chloride and the extracellular concentrations return to normal. In the last four cases shown in Table IV, therefore, at a time when chloride was available some other factors must have been conditioning the tubular reabsorption of this ion.

However, when chloride ion was administered rapidly and in large quantities as an acidifying salt, $\mathrm{NH}_{4} \mathrm{Cl}$, chloride was retained in sufficient amounts to raise its extracellular concentration to normal as the extracellular bicarbonate concentration was lowered. Simultaneously, the extracellular volume or chloride space expanded and sodium moved into it from the intracellular space. This occurred without any restoration of potassium to the cells. There are at least two interpretations of these transfers. One is that an excess of intracellular sodium may have made this adjustment possible. Another is that the kidney was unable to excrete at least part of the suddenly imposed load of extra anion with ammonia because of renal damage or because of the time lag inherent in the mechanism of ammonia formation. Under these circumstances, the transfer of cellular sodium (the only sodium available) was the only way to mitigate an otherwise abrupt change in acid-base equilibrium due to displacement of bicarbonate as $\mathrm{CO}_{2}$ through the lungs. Such a sodium transfer requires some accounting in regard to the intracellular anion pattern; this problem is discussed below. But whichever of the above interpretations is accepted, of the response to $\mathrm{NH}_{4} \mathrm{Cl}$, it would appear that if there is an obligatory relationship between the extracellular concentrations of chloride and bicarbonate and intracellular cation compositions, the relationship pertains more directly to intracellular sodium than to potassium.

According to the Darrow hypothesis, the direct withdrawal of chloride in excess of sodium by way of gastric fluid, resulting in a metabolic alkalosis, should produce changes in intracellular cation com- position even in the presence of an adequate intake of potassium. Unfortunately our data are incomplete on this point. Only in Patient $\mathrm{T}$. W. were balance studies obtained under such conditions. Intracellular potassium was diminished because of the loss in the gastric washings, but intracellular sodium was not increased. This may be accounted for by the presence of moderately severe renal insufficiency which certainly interfered with any renal readjustments that might have been made. Prior to study, Patient H. H. had lost a large amount of gastric fluid by lavage. Studies during his replacement therapy showed a very large decrement of cellular sodium as his bicarbonate concentration fell, without much retention of potassium. Thus under some circumstances extracellular chloride deficit and alkalosis probably can be produced without necessarily affecting either the sodium or potassium content of the intracellular phase. This is in agreement with the experience of Evans and co-workers who found in both surgical patients and in dogs that alkalosis could occur without cellular potassium depletion and could be corrected without the administration of this ion (31-33).

Darrow has suggested that the primary factor in extracellular fluid which conditions the intracellular electrolyte pattern is the concentration of hydrogen ion rather than that of bicarbonate or chloride. In support of this thesis he has cited his experiments (34) in which rats on exposure to low atmospheric pressures developed sodium excess and a questionable potassium deficit in the cellular phase of skeletal muscle. Presumably an alkalosis developed due to primary $\mathrm{CO}_{2}$ deficit with a lowered $\mathrm{CO}_{2}$ content of extracellular fluid, although no such measurements were made. We have studied patients representing the converse of this condition, namely, those with respiratory acidosis due to the primary retention of $\mathrm{CO}_{2}$ as a result of severe pulmonary disease. This condition leads to a secondary fall in chloride and rise in bicarbonate concentration as a response to the rise in level of carbonic acid. In a small series of such patients with marked elevations of serum bicarbonate concentration, but with low blood $p H$, the serum concentration of potassium was found to be uniformly within the normal range (35). This finding suggests, but does not prove, that no severe intracellular depletion of potassium coexisted 
with the high bicarbonate concentration found in respiratory acidosis. These studies are not adequate controls to those reported in this paper since the uptake of potassium administered to such patients was not tested. But they do suggest that intracellular electrolyte composition is conditioned not by concentrations of extracellular bicarbonate but by concentrations of hydrogen ion or carbonic acid. The latter is suggested by data of Wallace and Hastings (36) who found by direct analysis of muscle that the bicarbonate content of intracellular fluid is very little affected by the bicarbonate of the extracellular phase (the cell is impermeable to $\mathrm{HCO}_{3}^{-}$), the calculated intracellular $\mathrm{pH}$ being altered according to changes in $\mathrm{CO}_{2}$ pressure alone.

Extensive differential net transfers of cations versus anions between the two phases of body fluids require consideration of their effect on the ionic electrical neutrality and osmotic pressure of the respective phases. Knowledge of the ways in which electrical neutrality of intracellular fluid is maintained under these circumstances awaits at least the complete description of net exchanges across the cell boundary of the cations, calcium and magnesium, in addition to sodium and potassium, and of the anion, phosphate, as well as chloride. Some evidence on this score has been supplied by Gardner, MacLachlan and Berman (37) who found in the skeletal muscle of potassium deficient alkalotic rats, that the intracellular bicarbonate was decreased and phosphate increased, and that calcium and magnesium, as well as sodium entered the cellular phase. However, in addition to external transfers, metabolic processes and variations in cellular $\mathrm{pH}$ must affect the degree of dissociation of the organic phosphate and proteinate buffer system within the cell. Alterations in cellular osmolarity, so produced, apparently share in conditioning movements of water (38). Therefore, any complete accounting of the maintenance of electrical neutrality and of osmotic equilibrium is impossible with the data at hand.

From the study of these cases it appears to the authors that a variety of disturbances in intracellular cation pattern may exist in the presence of metabolic alkalosis, produced in a variety of ways. These disturbances may consist of $(a)$ a decrease in potassium and an increase in sodium, $(b)$ an increase in sodium without change in potassium, and $(c)$ a decrease in potassium without an increase in sodium. The first of these, $a$, is most common and is usually present when there has been over-activity of the adrenal cortex or when the intake of potassium has been very low for a prolonged period of time. Under the latter circumstance the kidneys continue to excrete potassium for a long enough period to produce a significant deficiency before renal conservation takes place. Likewise, prolonged loss of gastric fluid, usually associated with inadequate potassium intake, may become associated with a decrease in potassium and an increase in intracellular sodium. On the other hand abrupt and drastic disturbance of extracellular fluid composition, such as may occur with excessive vomiting or postoperative gastric lavage, may be associated with no intracellular changes or with other patterns of change such as $b$ or $c$ listed above. In such conditions are more likely to be found the renal changes described by Burnett, Burrows and Commons (12) leading to potassium wasting, and in such conditions is less likely to be found the steady state of biological equilibrium (Darrow's prerequisite to intracellular pattern, $a$ ). It would be hazardous, therefore, to predict the precise intracellular cation disturbances in any case of metabolic alkalosis without due consideration of the physiological and clinical circumstances of its origin.

\section{SUMMARY AND CONCLUSIONS}

By use of the balance technic the intracellular cation exchanges have been studied in ten cases of metabolic alkalosis during treatment.

In all but one of the cases potassium was retained in the intracellular phase. In seven of the ten cases the chloride balance was much more positive than that of sodium. On the assumption that chloride is extracellular, large amounts of sodium were calculated to have left the intracellular phase. In some patients the decrement of sodium was roughly equivalent to, and in others greatly exceeded, the increment of potassium.

The extracellular bicarbonate concentration fell to normal levels concurrently with the increase in potassium and decrease in sodium in the intracellular phase, in four cases. In three others when $\mathrm{NH}_{4} \mathrm{Cl}$ was given, the bicarbonate concentration fell and sodium was extruded from the cells prior to any significant uptake of potassium by the latter. 
In one of these cases no potassium was retained, and in one sodium entered cells as the alkalosis was corrected.

A variety of etiological factors appeared to be involved in this group of cases as follows: low potassium intake alone, two; low potassium intake plus gastrointestinal fluid loss, six; adrenocortical hyperfunction (ACTH therapy, carcinoma), two. No evidence of abnormal renal wasting of potassium was found and in two cases an extreme degree of conservation of the ion with $\mathrm{U} / \mathrm{P}$ ratios of less than 1.0 was observed.

It is concluded from these data that although decrease in potassium and increase in sodium is a common intracellular cation disturbance in metabolic alkalosis, other patterns of disturbance may occur, especially when the onset has been abrupt and renal adjustment has not taken place. Where there is an equilibrium state between extracellular bicarbonate concentration and intracellular cation transfers, the former is more directly linked to those of sodium than to those of potassium.

\section{REFERENCES}

1. Darrow, D. C., Schwartz, R., Iannucci, J. F., and Coville, F., The relation of serum bicarbonate concentration to muscle composition. J. Clin. Invest., 1948, 27, 198.

2. Darrow, D. C., Congenital alkalosis with diarrhea. J. Pediat., 1945, 26, 519.

3. Tarail, R., and Elkinton, J. R., Potassium deficiency and the role of the kidney in its production. $\mathrm{J}$. Clin. Invest., 1949, 28, 99.

4. Danowski, T. S., Austin, A. C., Gow, R. C., Mateer, F. M., Weigand, F. A., Peters, J. H., and Greenman, L., Electrolyte and nitrogen balance studies in infants following cessation of vomiting. Pediatrics, $1950,5,57$.

5. Lowe, C. U., Rourke, M., MacLachlan, E., and Butler, A. M., Use of parenteral potassium therapy in surgical patients. Pediatrics, 1950, 6, 183.

6. Burnett, C. H., Burrows, B. A., Commons, R. R., and Towery, B. T., Studies of alkalosis. II. Electrolyte abnormalities in alkalosis resulting from pyloric obstruction. J. Clin. Invest., 1950, 29, 175.

7. Kepler, E. J., Sprague, R. G., Clagett, O. T., Power, M. H., Mason, H. L., and Rogers, H. M., Adrenal cortical tumor associated with Cushing's syndrome. Report of a case with metabolic studies and remarks on the pathogenesis of Cushing's syndrome. J. Clin. Endocrinol., 1948, 8, 499.

8. Sprague, R. G., Power, M. H., Mason, H. L., Albert, A., Mathieson, D. R., Hench, P. S., Kendall, E. C., Slocumb, C. H., and Polley, H. F., Observations on the physiologic effects of cortisone and ACTH in man. Arch. Int. Med., 1950, 85, 199.

9. Eliel, L. P., Pearson, O. H., and Rawson, R. W., Postoperative potassium deficit and metabolic alkalosis. New England J. Med., 1950, 243, 471, 518.

10. Mudge, G. H., and Vislocky, K., Electrolyte changes in human striated muscle in acidosis and alkalosis. J. Clin. Invest., 1949, 28, 482.

11. Kennedy, T. J., Jr., Winkley, J. H., and Dunning, M. F., Gastric alkalosis with hypokalemia. Am. J. Med., 1949, 6, 790.

12. Burnett, C. H., Burrows, B. A., and Commons, R. R., Studies of alkalosis. I. Renal function during and following alkalosis resulting from pyloric obstruction. J. Clin. Invest., 1950, 29, 169.

13. Wallace, W. M., Holliday, M., Cushman, M., and Elkinton, J. R., The application of the internal standard flame photometer to the analysis of biological material. J. Lab. \& Clin. Med., 1951, in press.

14. Eisenman, A. J., A note on the Van Slyke method for the determination of chlorides in blood and tissue. J. Biol. Chem., 1929, 82, 411.

15. Harvey, S. C., The quantitative determination of the chlorids in the urine. Arch. Int. Med., 1910, 6, 12

16. Van Slyke, D. D., and Stadie, W. C., The determination of the gases of the blood. J. Biol. Chem., 1921, 49, 1.

17. Brod, J., and Sirota, J. H., The renal clearance of endogenous "creatinine" in man. J. Clin. Invest, 1948, 27, 645.

18. Bonsnes, R. W., and Taussky, H. H., On the colorimetric determination of creatinine by the Jaffe reaction. J. Biol. Chem., 1945, 158, 581.

19. Harrison, H. E., A modification of the diphenylamine method for determination of inulin. Proc. Soc. Exper. Biol. \& Med., 1942, 49, 111.

20. Holtorff, A. F., and Koch, F. C.. The colorimetric estimation of 17-ketosteroids and their application to urine extracts. J. Biol. Chem., 1940, 135, 377.

21. Elkinton, J. R., Winkler, A. W., and Danowski, T. S., Transfers of cell sodium and potassium in experimental and clinical conditions. J. Clin. Invest., 1948, 27, 74.

22. Elkinton, J. R., Hunt, A. D., Jr., Godfrey, L., McCrory, W. W., Rogerson, A. G., and Stokes, J., Jr., Effects of pituitary adrenocorticotropic hormone (ACTH) therapy. J. A. M. A., 1949, 141, 1273.

23. Darrow, D. C., The retention of electrolyte during recovery from severe dehydration due to diarrhea. J. Pediat., 1946, 28, 515.

24. Danowski, T. S., Peters, J. H., Rathbun, J. C., Quashnock, J. M., and Greenman, L., Studies in diabetic acidosis and coma, with particular emphasis on the retention of administered potassium. J. Clin. Invest., 1949, 28, 1.

25. Conway, E. J., Exchanges of $\mathrm{K}, \mathrm{Na}$ and $\mathrm{H}$ ions between the cell and its environment. Irish J. M. Sc., 1947, p. 593. 
26. Dean, R. B., Theories of electrolyte equilibrium in muscle. Biol. Symposia., 1941, 3, 331.

27. Wilde, W. S., The chloride equilibrium in muscle. Am. J. Physiol., 1945, 143, 666.

28. Burch, G. E., Threefoot, S. A., and Ray, C. T., Rates of turnover and biologic decay of chloride and chloride space in the dog determined with the longlife isotope, $\mathrm{Cl}^{26}$. J. Lab. \& Clin. Med., 1950, 35, 331.

29. Pitts, R. F., Ayer, J. L., and Schiess, W. A., The renal regulation of acid-base balance in man. III. The reabsorption and excretion of bicarbonate. J. Clin. Invest., 1949, 28, 35.

30. Singer, R. B., Clark, J. K., Crosley, A. P., Jr., and Elkinton, J. R., Unpublished studies.

31. Evans, E. I., Potassium deficiency in surgical patients : its recognition and management. Ann. Surg., 1950, 131, 945.
32. Van Slyke, K. K., and Evans, E. I., The paradox of aciduria in the presence of alkalosis caused by hypochloremia. Ann. Surg., 1947, 126, 545.

33. Evans, E. I., Personal communication.

34. Darrow, D. C., Changes in muscle composition in alkalosis. J. Clin. Invest., 1946, 25, 324.

35. Singer, R. B., and Elkinton, J. R., Unpublished data.

36. Wallace, W. M., and Hastings, A. B., The distribution of the bicarbonate ion in mammalian muscle. J. Biol. Chem., 1942, 144, 637.

37. Gardner, L. I., MacLachlan, E. A., and Berman, H., Carbon dioxide, inorganic phosphate and cation content of muscle in potassium deficiency. Federation Proc., 1950, 9, 175.

38. Elkinton, J. R., Winkler, A. W., and Danowski, T. S., Inactive cell base and the measurement of changes in cell water. Yale J. Biol. \& Med., 1944, 17, 383. 